\title{
VARGAS, NOVELA ESPAÑOLA DE BLANCO WHITE
}

\author{
Rubén BENÍTEZ \\ Universidad de California (Los Ángeles)
}

Desde 1822, fecha de su publicación en Londres, Vargas. A Tale of Spain ha sido obra atribuida a José María Blanco White. Antes de argumentar en favor de esa atribución, conviene recordar que Blanco White evidencia en muchos momentos su interés por los géneros narrativos. Es autor de una novela inconclusa de tipo sentimental, Luisa de Bustamante o la huérfana española, publicada por primera vez en 1859 , y de varios relatos breves recogidos en Variedades o el Mensajero de Londres, como Costumbres húngaras; Historia verdadera de un militar retirado, con una descripción de un viajito, río arriba, en el Támesis; Intrigas venecianas o Fray Gregorio de Jerusalén. Ensayo de novela española; El Alcázar de Sevilla (Prat, 1975); La marca en la frente se publicó como Apéndice VI en el tomo III de la Vida (Blanco White, 1845) y Atmos, the giant en un libro editado por Lady Fox (Blanco White, 1833).

Entre 1822 y 1823 , Blanco White ensayaba un tipo distinto de narraciones, en las que se asociaban la historia, el costumbrismo y la creación imaginativa. Preparaba entonces una novela sobre la corte de Juan II y el privado D. Alvaro de Luna, de acuerdo con un plan similar al de Vargas: los materiales proporcionados por las fuentes históricas, en ese caso el falso Centón epistolario y la obra de Juan de Mena, se volcarían sobre el marco de la descripción de usos y costumbres de la época. Blanco se refiere a esa obra en la carta a Robert Southey que recoge Vicente Llorens. En nota, Llorens aclara que ese relato nunca se terminó, pero que los materiales fueron usados en artículos aparecidos en New Monthly Review y en el mismo periódico de Blanco, el ya citado Variedades, entre 1823 y 1825 (Llorens, 1972, pág. 151, nota 17).

En 1839 imagina otra novela, Diario secreto de un Inquisidor español o Aberraciones religiosas, cuyo argumento resume: Un sincero sacerdote católi$\mathrm{co}$, muy ilustrado y de refinado espíritu, es designado inquisidor al llegar a los treinta años de edad. Hombre de claro razonamiento y de un auténtico amor por la verdad, interroga a los prisioneros en privado tratando de descubrir la legitimidad de los distintos credos religiosos. Sus crecientes dudas lo alejan 
poco a poco del Catolicismo. Se convierte pues en deísta, y la Inquisición lo encierra en sus prisiones. En la cárcel descubre a una hermosa joven judía de la que se enamora. Para salvarla, arriesga la vida, sufre persecución y termina por ser víctima de la llamada cristiandad (Blanco White, 1845, III, pág. 103). Debe de tratarse del mismo Spanish Tale que el autor está componiendo en 1839; de ser así, el relato incluiría, como Vargas, ejemplos de costumbres y de poesía popular, según se desprende de esta anotación en el Diario del 21 de Octubre: "Escribí ayer a la mañana dos seguidillas en conexión con el personaje de una joven española que pienso desarrollar en un Spanish Tale" (Blanco White, 1845, III, pág. 108). Dadas las fechas, pudo ser también ésa la novela que leía a su sobrina Mary Anne, el 14 de Noviembre de 1839. ¿Pertenecerían al mismo relato los fragmentos españoles que, ya muy enfermo, entregó a Zulueta para que los concluyera según un plan verbalmente transmitido (Blanco White, 1845, III, pág. 222).

Si esa obra proyectada se desarrollara en Sevilla, tendríamos casi una réplica de Vargas. El asunto gira en los dos casos alrededor de la inquisición y del fanatismo católico; el joven sacerdote sevillano es ahora un inquisidor, y Cornelia se ha transformado en una hermosa judía.

Llorens nos proporciona el título de otras dos novelas inconclusas con títulos muy similares al de Vargas: Contreras. A Spanish Tale of the 15th. Century y The Tainted Blood, a Spanish Tale (Llorens, 1971, pág. 151 y nota 17) ${ }^{\prime}$. Tale se denomina también el relato Atmos, the giant, escrito en Junio de 1832, que nada tiene que ver con sucesos históricos (Blanco White, 1833, pp. 190-216).

Pero Blanco White no menciona Vargas, ni en su Vida ni en su diario personal, que, como advierte Martin Murphy, conocemos sólo muy parcialmente (Murphy, 1989, pág. 195). Ese silencio ha sido interpretado como prueba de que no es el autor de la novela; para mí, por el contrario, confirma su autoría. Blanco sabía que algunos amigos, e incluso un conocido crítico, le adjudicaban esa obra, privada y públicamente. ¿Cómo un hombre tan celoso de su reputación dejó correr ese rumor, si es que era infundado, sin salirle al paso o defenderse? El manuscrito fue entregado al editor Baldwin, quizá por necesidades económicas, antes de la aparición de las Cartas de España ${ }^{2}$; más tarde, según el testimonio de William Walton que analizaré más adelante, el autor quiso detener infructuosamente la impresión del libro. Es para mí evidente que el inesperado éxito de crítica de las Cartas contribuyó al mantenimiento del incógnito. Desde entonces y hasta 1825 , Blanco se dedica casi de lleno a la literatura "seria"; en el nuevo planteamiento de su vida, impuesto por la creciente fama, nada tenía que hacer, en ese momento, el aún poco prestigioso género de la novela.

1. Vicente Llorens nos proporciona una completa bibliografía del autor, incluidos esos manuscritos nunca publicados. Ver además Blanco White, 1845, pág. 496.

2. Cito, en lo sucesivo, por la edición inglesa de las Cartas; pero hay una versión española de Antonio Garnica con prólogo de Vicente Llorens, según indico en la Bibliografía. 
El primero en atribuir la obra a Blanco White, en España, fue Mario Méndez Bejarano en 1920. Bejarano conoció su existencia a través del catálogo de la Biblioteca del British Museum, donde se adjudica a Blanco con la nota siguiente "Vargas. Novela española. Atribuida en el Prefacio a Cornelius Villiers, pero en verdad escrita por José María Blanco y Crespo". Esa nota del Catálogo no es de desestimar; el catalogador del British Museum suele ser un bibliógrafo eminente, y la catalogación un resultado de serias pesquisas ${ }^{3}$.

Bejarano propone como prueba de su atribución el citado testimonio de Walton, en esta carta, algo mal traducida:

St. Oswald Lodge. Warcester. Octubre, 3, 1855. Muy señor mío: Desde la tarde de mi salida de Oxford no me ha sido posible contestar a su carta del 28 del pasado, proponiéndome desempeñar aquí tan agradable ocupación. Deseando V. ver el primer volumen de Vargas, pensé que lo mejor sería enviar los tres a Mr. Macray, rogándole que se lo remitiera cuando supiera de V., lo que probablemente haría cuando usted recibió mi comunicación.

Añadía yo un curioso folleto español, reimpreso en Londres por Correa, a la vez protegido y amigo mío particular. A la vuelta de Fernando fue entregado por el gobernador de Gibraltar, encarcelado y víctima de malos tratamientos. Habiendo podido escapar y refugiarse en Inglaterra, yo trabajé para conseguirle una indemnización por la conducta del gobernador y llegó a ser un ostensible carácter. Esta publicación se vendió mucho, pero distribuida entre algunos amigos de la causa española.

Vargas, como antes decía, está en cierto modo fundado en esto, y la apreciación de uno puede no ser exacta sin tener en cuenta la del otro. Entonces consideraban a Blanco autor de Vargas todas las personas versadas en asuntos españoles, entre ellas Lord Holland. El editor de la obra, o sea Baldwin, hablando conmigo, me lo confesó más de una vez, no obstante el velo con que trata de encubrirlo en el prefacio. Nadie más que un español, y sobre todo un sevillano, pudiera haber escrito semejante obra. Si no recuerdo mal, B. White entregó la copia en cuestión; pero algún tiempo después se arrepintió de haberla escrito y procuró hacerla desaparecer.

Esto es lo que puedo recordar respecto al autor. V., no obstante, juzgue por sí mismo. Mr. Macray cumplirá su deseo cuando sepa de V.

Su atento s.s. W. Walton.

En el sobre se leen las siguientes señas: "Benjamín B. Wiffen Esq. Near Woburn. Bedfordshire" (Méndez Bejarano, 1920, pág. 439).

Benjamin B. Wiffen era un estudioso de la vida y obra de los heterodoxos y reformistas españoles; Llorens cuenta sus vicisitudes cuando intentó comprar los libros raros que poseía Don Miguel de Riego, exiliado español en Londres (Llorens, 1954, pp. 48-49). En 1874 se publica la Biblioteca Wiffeniana, dedicada a reformistas españoles de los siglos XVI y XVII (Bohemer, 1874). No extraña pues ese interés por Vargas, que actualiza en cierto sentido la historia de Antonio Pérez, el ministro de Felipe II. Ese Wiffen era hermano

3. Copian esa misma nota repertorios más modernos como la Addenda al volumen IX de Halkett 1917, pág. 355. 
además de Jeremiah H. Wiffen, traductor de Garcilaso de la Vega y bibliotecario de Lord John Russell, el protegido de Lord Holland, a quien Blanco conocía; y hacia las fechas en que se publicó Vargas, J. H. Wiffen consultó con Blanco detalles de esa traducción (Murphy, 1989, pág. 120).

William Walton debía de conocer personalmente a Blanco White. Era hombre muy versado en asuntos hispánicos, sobre todo en aquellos relacionados con los intereses económicos de Inglaterra. Publicó un libro titulado El estado actual de las colonias españolas, obra que, según Robert Southey, fue reseñada por Blanco White para el Quarterly Review (Curry, 1965, pág. 38, nota 3$)^{4}$. Walton murió en Oxford dos años después de escribir la carta, en 1857 (Stephen, 1986, págs. 737-738).

El "curioso folleto español" al que Walton se refiere, y que según él tiene estrecha relación con Vargas, es a mi juicio la novelita Cornelia Bororquia (si es que folleto es, como pienso, una mala traducción de la palabra inglesa booklet.) De ser así, el editor Correa, mencionado en la carta, puede ser el que en las reimpresiones londinenses se oculta como Don A.C. y G. (Dufour, 1987, pp. 53-55)

Martin Murphy, en su biografía de Blanco White, trae una segunda prueba de la autoría de Vargas: la reseña de John Gibson Lockhart aparecida en Blackwood's Edinburgh Magazine (Murphy, 1989, pág. 120) ${ }^{6}$. Lockhart, autor de Ancient Spanish Ballads; Historical and Romantic (1823) y de una autorizada biografía de Walter Scott, era el yerno de éste y formaba parte del grupo intelectual de Edinburgo, con el cual tenían muy estrecha relación Lord Holland y su hijo, Henry Edward Fox, discípulo de Blanco ${ }^{7}$. Southey da indicios de que Lockhart tenía familiaridad con Blanco White, pues en las muchas cartas que dirige al primero de ellos se refiere a Blanco con frecuencia, sin necesidad de explicar las alusiones y sobreentendidos.

Para comprender el valor de la reseña de Lockhart muy extensa y favorable, debe recordarse que el Blackwood's Edinburgh Magazine, llamado así por ser Blackwood su editor, era una de las cuatro revistas de mayor importancia en aquel entonces ${ }^{8}$. Nada dice, en cambio, sobre Vargas, el Quarterly Review; no es extraño, ya que nunca publicaba reseñas breves. The Gentleman's Magazine comenta extensamente las Cartas de "Leucadio Doblado", en Noviembre de 1822, y publica una breve nota sobre el periódico Variedades o El Mensajero

4. Vol. VII, carta de Agosto de 1812. Ha estudiado bien las ideas de Blanco White sobre la colonia, Moreno Alonso, 1993.

5. Gerard Dufour identifica dos ediciones londinenses, una de 1819 y otra de 1825 , con esas mismas iniciales.

6. Lockhart fue acerbamente criticado por su colaboración con el editor Blackwood. Ver al respecto los capítulos IV y V de Lang, 1897.

7. Hay muchas referencias al grupo de Edimburgo, a Walter Scott y a su hija Mrs. Lockhart y a Lockhart mismo en Fox, 1923, especialmente págs. 115 y 122.

8. Ha sido para mí muy útil el Capítulo VI, "Reviews and magazines in the early years of the Nineteenth Century", escrito por A.R.D. Elliot en The Cambridge History of English Literature, 1964. 
de Londres, en Diciembre de ese mismo año (pp. 446-447 y 548). Pero no da noticia alguna sobre Vargas. The Monthly Review, la revista menos politizada del conjunto, que es la que dió a conocer algunas de las Cartas de "Doblado", informa sobre la aparición del volumen que las recoge en su "Literary Report" del 1 de Julio de 1822 y en "New Publications with Critical Remarks", del 1 de Agosto, reseña con mucha simpatía el volumen (pp. 230, 361-362). En la misma sección, 1 de Octubre, aparece una pequeña nota sobre Vargas: "Esta novela, como lo supone el título, pinta las costumbres de España, y su asunto tiene conexiones con la historia española; pero parecería que la ficción literaria es género nuevo para el autor. El estilo es rígido y pobre y los incidentes se cuentan, pero no se presentan; contiene, sin embargo, pasajes que permiten un favorable augurio con respecto a la habilidad del autor y no dudamos de que serán mejores sus frutos cuando adquiera más práctica" (pág. 461). La breve nota no nos permite saber si los editores de la revista sabían o no que se trataba de Blanco White, aun cuando la frase que he subrayado resulta sospechosa; el autor de la nota indica que es un primer intento novelístico, y nada en la novela permite suponerlo. La reseña del Blackwood's Edinburgh Magazine es, pues, si no el único, como dice Murphy, sí el más completo comentario de la novela. Se trata de una extensa e interesante nota crítica, la primera comparación que conocemos entre un novelista español y Walter Scott. Ahora sólo interesa el párrafo que Murphy transcribe en inglés:

Las Cartas de Don Leucadio Doblado, (id est según creemos, Mr. Blanco White), que originalmente aparecieron en el New Monthly Magazine, y que han sido publicadas recientemente en volumen separado, son de alto interés. Están escritas con gran simplicidad y al mismo tiempo con elegancia, y el cuerpo de información que contienen corresponde en valor al estilo en que están escritas. No tenemos modo de aseverar si esta novela, que está ahora sobre nuestra mesa de trabajo, es obra o no del mismo cumplido caballero. Sea de quien fuere, merece más atención que la que hoy se otorga a obras de esta especie. Evidencia un certero conocimiento de las viejas costumbres de España y de los sentimientos y personajes de la época; y aunque el autor muestra poca pericia en el modo de estructurar su historia, escribe con una energía que corre a través de los volúmenes sin hacernos perder el interés. En una palabra, si este libro hubiera aparecido hace diez años habría producido una sensación (Murphy, 1989, pp. 120-121).

Ésas son las dos únicas pruebas externas sobre la paternidad de Vargas. Son pruebas indirectas y ninguna de las dos constituye una evidencia rotunda. Pero los datos que sobre los autores de esas notas he recogido más arriba sirven para reafirmar que se trata de intelectuales muy conocidos en Inglaterra, relacionados con Blanco White o con el círculo de sus amigos, y que tuvieron por consiguiente más oportunidad que nosotros para recabar de fuentes muy cercanas la verdad sobre esa autoría. Sus opiniones son por lo menos conjeturas serias, bien fundadas y basadas en la opinión general de ese momento.

9. La reseña aparece sin nombre del autor en el vol. XII del Blackwood's Edinburgh Magazine. Abarca 10 páginas (730-740), extensión inusitada en notas de ese tipo. Tras proporcionar un extenso resumen del argumento, se compara Vargas con la obra de Walter Scott y se transcriben dos capítulos enteros de lá novela. La nota está sálpicada de importantes observaciones críticas. 
Hay que reconocer, sin embargo, que no son pruebas suficientes para contrarrestar la fuerza que tiene, para cualquier estudioso de la literatura española del siglo XIX, la opinión de Vicente Llorens, es decir de quien conocía más y mejor la obra de Blanco White. Llorens refuta la atribución de Bejarano en la siguiente nota de su Antología: "Atribución errónea: M. Méndez Bejarano, op. cit., fundándose en recuerdos personales de William Walton de 1855, y el Catálogo de la biblioteca del British Museum, atribuye a Blanco la novela Vargas, a Tale of Spain, London, 1822, no obstante indicarse en el prefacio que era obra de un tal Cornelius Villiers. Los diarios de Blanco y su correspondencia, aparte del estilo de la obra, prueban que tal atribución es insostenible. Sólo en 1823 empezó a escribir una novela en inglés, que no acabó" (Llorens, 1971, pág. 58). No hay duda sobre lo erróneo de esa afirmación, pues Cornelius Villiers es un personaje novelesco y no un ser real. Me parecen mucho más convincentes que las indicadas pruebas, sin embargo, los argumentos que surgen de la comparación de la novela con otras obras del mismo autor. Para no abundar en ejemplos, algunos de los cuales comenta ya Bejarano, baste indicar los contactos de mayor evidencia. Los usos y costumbres a los que el novelista confiere más atención son también puntos claves de las Cartas de España; pero la explicación de frases coloquiales como pelar la pava o gente de paz, de fórmulas oficiales como nobles por los cuatro costados o hidalgos de casa y solar conocido, o de costumbres muy sabidas como la de dormir la siesta, podría figurar en el libro de cualquier viajero inglés interesado en describir la vida andaluza. Una curiosa observación, que por rara torna indudable la presencia del mismo autor en ambos textos, es la coincidencia que Blanco White observa entre la lengua española y la griega; en la novela se habla de esas similitudes en general (Blanco White, 1822, pág. 53); las Cartas se refieren particularmente a las formas de cortesía usadas para convidar a un banquete (Blanco White, 1822b, pág. 328). No olvidemos que el seudónimo "Leucadio Doblado" une un término español a uno de raíz griega. Una costumbre religiosa, los rituales que rodean el paso del Viático, destaca tanto en las Cartas como en Vargas, por su extensa explicación. El relato de Blanco White en las Cartas se basa en un hecho real que le ocurrió durante su visita a Cádiz; por consiguiente los detalles provenientes de esa experiencia personal no podrían haber sido repetidos en otro texto por alguien ajeno a esa misma experiencia. Dice en las Cartas que el sonido de la campanilla de mano anunciando la llegada de la hostia consagrada obliga al transeúnte a retroceder o a arrodillarse en el fango hasta que el sacerdote, que lleva la hostia para ser ofrecida a un moribundo, esté en el punto más alejado del lugar donde comenzó a escucharse el campanilleo. La regla en esa ocasión es expresada en la frase proverbial Al Rey viéndolo; a Dios, oyéndolo. Dios y el Rey están acoplados en el lenguaje del lugar por el mismo título de Majestad que se les aplica. Un día en Cádiz, al acercarse el Viático, Blanco procura apartarse. Un gallego, al ver su indiferencia, le advierte amenazadoramente que se trata de Dios, Su Majestad. Blanco White intenta retroceder, pero el gallego repite tres o cuatro veces la frase, lo empuja al suelo y expresa a voz en cuello esta temible acusación: "Este hombre es un herético". Los actores de teatro y los bailarines de fandan- 
go -agrega Blanco- deben interrumpir su actuación al oír la campanilla" (Blanco White, 1822a, pp. 10-14).

En Vargas, el gitano que se dirige a la Inquisición detiene su marcha ante una pareja de bailarines que al son de la guitarra bailan precisamente el fandango. Ya cerca de las puertas de la ciudad, oye un cascado tambor que repite la información dada por una tintineante campanilla; el Viático se aproxima. "iSu Majestad! ;Su Majestad!", musita la gente. Y el autor aclara "Éste es el más alto tratamiento que se dispensaba entonces y se dispensa hoy en España a sus Majestades, Dios Todopoderoso y el Rey, unidos en esa familiar apelación". En una nota a pie de página atribuye a la arrogancia de Carlos V la invención de ese uso en tiempos en que tal tratamiento se aplicaba sólo a Dios.

Al gitano le ocurre exactamente lo mismo que a Blanco White. La gente cae arrodillada; el gitano permanece de pie y una devota mujer le tira de la capa y le dice: "¡Señor... Su Majestad!" Como el gitano intenta retroceder, la mujer grita con vehemencia: “UUn herético! ¡Un herético que rehusa adorar a Su Majestad!" El gitano, como el autor de las Cartas, intenta borrar con gestos toda sospecha de herejía (Blanco White, 1822b, pp. 294-295).

También son de carácter eminentemente personal las observaciones sobre el paisaje de la ruta que va de Madrid a Sevilla. Blanco White hace ese viaje en Julio de 1812: "No había modo de llegar a Andalucía -dice en las Cartas- sin atravesar la provincia de Extremadura; y no existía otro transporte, en ese tiempo, que dos coches aragoneses que, por parar en una pequeña venta a tres millas de Madrid, estaban fuera del contralor inmediato de la policía francesa" (Blanco White, 1822/a, pág. 425). Sale de Madrid, sin equipaje, en pleno verano, y recorre penosamente el trayecto hasta Extremadura. Vargas sigue en la novela el mismo itinerario, también en el mes de Julio, pero un año después, en 1813. La coincidencia del viaje del personaje con el del autor, efectuados ambos en las mismas condiciones y bajo el rigor del mismo clima veraniego, favorece la acertada descripción, paso a paso, de las fatigas y vicisitudes del camino; el novelista no hace más que objetivar sus recuerdos personales.

El paisaje más detenidamente descrito es el de Sierra Morena. La sierra, que separa Andalucía de la Mancha, se levanta abruptamente ante Vargas al llegar a Alange. Se trata de unas colinas rocosas de difícil acceso por los cuatro lados, que se vuelcan en forma de precipicio sobre el llano. Esas mismas estribaciones aparecen descritas en las Cartas desde la otra ladera, cuando el autor pasa por las cercanías de Córdoba para dirigirse a Madrid. En una de las colinas de la Sierra ve Blanco White, y lo dice en las Cartas, unas miserables casuchas habitadas por ermitaños. Las dimensiones de esas casuchas proporcionan apenas espacio para unas tarimas, que levantadas a un pie del suelo y cubiertas de una felpa sirven de lechos, para un asiento triangular y para una diminuta mesa en que descansan un crucifijo, una calavera humana y uno o dos devocionarios. La puerta es tan baja que nadie puede traspasarla sin inclinarse (Blanco White, 1822, pág. 234). Vargas visita al Fray Lorenzo en una casucha similar, situada en un idéntico paisaje; su celda presenta las mismas caracterís- 
ticas y hasta algunos de los mismos utensilios observados en el interior de esas ermitas (Blanco White, 1822b, pp. 194-195 y 354).

Cerca del castillo de Alange descubre Vargas una cruz rodeada de montículos de piedrecillas, arrojadas por fray Lorenzo después de hacer sus penitencias. Blanco White no hace más que animar allí novelescamente lo que dice en las Cartas respecto a las cruces y montículos de piedra que honran, en los caminos de España, a las víctimas de asesinatos. Con citas de Hamlet y del Libro de los Proverbios muestra que ese raro hábito conservado en España era común antiguamente en otros países de Europa y supone que se habría originado en la costumbre judía de apedrear a los condenados. Los cristianos modernos aplicaron el uso a las tumbas de quienes no merecían ser enterrados en sagrado; y, con la frecuencia de robos y asesinatos en los caminos de España, se unió a la vieja costumbre la idea del crimen (Blanco White, 1822a, pp. 320321). No es extraño, pues, que la rústica cruz de piedra en la novela marque el sitio en que fray Lorenzo arrojó presuntamente al heredero de los Dávila, y que ante esa cruz fray Lorenzo se discipline y arroje luego una piedra por cada Padre Nuestro (Blanco White, 1822b, pp. 145-146).

Otra experiencia absolutamente personal, e inusitada en autores de su tiempo, se refleja en las Cartas y en la novela con indudables coincidencias, me refiero al magnífico testimonio de Blanco White sobre los motines populares. En Mayo de 1808, Blanco vivía en Madrid, en una casa cercana al Parque de Artillería. Asiste a preparativos del ejército francés y las escaramuzas de la población madrileña. Al salir a la calle, ve en sus últimos momentos al herido Daoiz, compueblano y conocido suyo, que al pasar a su lado en la camilla parece reconocerlo (Blanco White, 1822a, pp. 402-403). Esas páginas están estremecidas de vida, y denotan la moderna sensibilidad de un autor contemporáneo de la Revolución Francesa. Evidencian además un palpable interés por analizar la formación de los motines y el comportamiento de la muchedumbre. En Vargas, los movimientos populares de Zaragoza con motivo de la prisión y del vergonzoso proceso de Antonio Pérez aparecen descritos del mismo modo y con particularidades y detalles que crean la ilusión de una observación directa (Blanco White, 1822b, cap. II y pp. 367-374). Es evidente que Blanco White transporta en esos pasajes sus experiencias de 1808, vivificando la información de las crónicas con una más moderna intelección del proceso de las revoluciones populares. Las páginas de Vargas complementan así las de las Cartas, y ambos textos constituyen el mejor testimonio contemporáneo de las asonadas revolucionarias de la masa española; esas páginas merecerían ser ilustradas con las pinturas negras y los grabados de Goya, inspirados en hechos similares.

Si todavía quedaran dudas sobre la paternidad de Vargas, sería fácil disiparlas con dos ejemplos más. En las Cartas se cuenta el milagro de un dominico que sufre de parto, del modo siguiente:

El santo, nativo de Valencia y monje de la orden de Santo Domingo, poseía el don de los milagros en tal grado que los hacía casi inconscientemente y muy a menudo en forma de travesura. En cierta ocasión, se le acercó una joven casada a quien la idea 
de su próxima maternidad la había sumido en un estado de terror; el buen santo quiso quitarle esos temores diciéndole que él asumiría cualquier inconveniente o problema que sobreviniera en su parto. Pasaron algunas semanas y el buen monje, que había olvidado su promesa, comenzó al alba a lanzar aullidos y quejidos de modo tan poco usual y tan poco apropiado para un santo profesional, que toda la comunidad se llegó a su celda... El agradecido marido de la dama que originó ese alboroto vino poco después a agradecerle su "inconsciente" ayuda en el parto de su consorte (Blanco White, 1822a, pp. 317-318).

En Vargas, se atribuye el mismo milagro al padre Nicolás de la Ermita del Punto:

Baste contar en resumen una extraordinaria circunstancia y referir al lector a los archivos de la Catedral de Sevilla para verificar la verdad de lo que digo. Una mujer que estaba a punto de ser madre, pidió al santo que la eximiera, si era posible, de los dolores que le esperaban. El buen ermitaño, tras recordarle la maldición original que pesaba sobre su engañoso sexo, la instó a que aceptara el sufrimiento. ¿No podría usted sufrirlo por mí, santo padre? -preguntó la tímida hija de Eva. Por qué clase de convencimiento lo logró, no se sabe, ni hay de ello constancia en los archivos sevillanos, pero sabemos que el padre consintió y que la mujer se fue de allí muy satisfecha. Pasó el tiempo y el ermitaño, quizá sin saber lo que había prometido, se olvidó de ello hasta que un día, mientras oficiaba la misa en su capillita, le volvió el asunto a la memoria a raíz de los terribles dolores que lo acuciaron a intervalos y por muchas horas. En ese mismo tiempo, la mujer dio a luz dos mellizos sin el menor dolor ni inconveniencia alguna (Blanco White, 1822b, pp. 251-252).

La conversión de Vargas al protestantismo está basada en el vivo recuerdo que tiene Blanco White de su propia conversión. Vargas queda admirado de la sencillez del culto anglicano, cuya belleza crea en él un estado espiritual receptivo y propicio al cambio, sobre todo al escuchar el Salmo LXV, Jubilate Deo Omnis. (Blanco White, 1822b, pp. 107-108). Ese pasaje de la novela repite punto por punto la descripción que hace Blanco White de similar experiencia en su Preservativo contra Roma, en un párrafo bien conocido desde que Menéndez Pelayo lo transcribió en su Historia de los heterodoxos españoles (1932, VII, pp. 190-191 y nota ${ }^{10}$. Blanco destaca allí también la sencillez de las ornamentaciones y de los rituales y la sobrecogedora impresión que le causó oír el mismo Salmo $L X V$ cantado en inglés.

Con respecto a otras prácticas religiosas, las similitudes entre la novela y las obras de Blanco White son tan numerosas y tan claras que no merecen discusión. La crítica expresada en la Vida con respecto a la confesión auricular (u oral) sirve para explicarnos la ambivalente actitud de Vargas al escuchar las confidencias de la marquesa de Montemolín en sus últimos momentos. La opinión de Blanco sobre la extremada devoción por los santos y las imágenes, sobre todo en Andalucía, constituye la base sobre la que se asientan sus ironías

10. Menéndez y Pelayo traduce de la 2ª edición (Blanco White, 1834). En la pág. 193 indica la existencia de dos versiones españolas, uná de 1856 y otra de 1868, atribuidas a Luis Usoz del Río. 
sobre la devoción del padre Cacafuto y de los demás personajes, encomendados siempre a sus santos predilectos. La descarnada actitud del Arzobispo hacia Cornelia es un ejemplo de la equívoca relación entre sacerdotes y devotas, que Blanco White, basado en su experiencia y la de una de sus hermanas, fustiga constantemente. Y por último, en materias más propias del dogma, Blanco White se refiere en todos sus escritos, incluso en Vargas, al misterio de la transubstanción, a la superchería de los milagros, al absurdo uso de disciplinas, a los tormentos inquisitoriales, a los excesos de la vida ascética y a los delirios místicos de los eremitas.

No extraña pues que tanto el personaje de la novela como el narrador ficticio Cornelius Villiers sean dobles de "Leucadio Doblado". Cornelius Villiers parece otro seudónimo de Blanco White: Cornelius recuerda a Cornelia, víctima de la Inquisición; y Villiers, llamado también Correvillas, es un andariego Juan sin Tierra que padece un doble exilio. Villiers está vinculado, los mismo que Blanco, con Sevilla y con Cádiz. Destinado desde niño a la Iglesia, abandona los estudios de la Universidad y entra como tenedor de libros en la firma de uno de sus parientes (que comercia entre otras cosas con lana), donde trabaja durante 10 años. Odia la vida de comerciante. Blanco White, como se recordará, entra a los ocho años a trabajar con el padre y los tíos en el comercio de exportación de lanas. Está allí ocupado por 6 años, ya que a los catorce pasa a la Universidad. Autor y personaje sienten fastidio ante las notas de crédito y otros documentos similares de la vida mercantil. Tanto Cornelius como Blanco White dan directo testimonio de la Guerra Peninsular y ambos recuerdan a los amigos con quienes compartieron inquietudes intelectuales y con quienes leyeron crónicas españolas sentados bajo el naranjal de la Cartuja de Sevilla.

El personaje principal de la novela es también sevillano y participa de la misma formación religiosa; estudia para el sacerdocio, como Blanco White, en el Colegio Mayor de Sevilla, y llevado también él por el acuciante deseo de saber, pone en duda las verdades teológicas, sobre todo la inconsistente doctrina de la infalibilidad, que Blanco White discute en varios lugares. Esa constante reflexión crítica le hace perder la fe. El establecimiento de Vargas en Inglaterra sigue los pasos, salvadas las diferencias de siglos, de la llegada y la lenta integración de Blanco en la vida londinense. Ambos son instructores de niños pertenecientes a familias ricas y poco a poco van estableciendo relaciones del más alto nivel. Pero sobre todo coinciden, como hemos visto, en su conversión al protestantismo.

No creo en la necesidad de aducir más pruebas. Si la novela no fuera de Blanco White habría que probar la existencia en Londres, en ese mismo momento, de un sacerdote sevillano convertido al protestantismo que tuviera con Blanco White tantos puntos de contacto en su pensamiento y en su obra como los que hemos indicado. Conste que las Cartas conocidas a través de la publicación periodística no son todas las que se recogen en volumen en el mimo momento en que Vargas está en prensa. Nadie más que el autor podía 
conocer por consiguiente aquellas cartas aún inéditas en que aparecen muchas de las coincidencias indicadas.

Según Méndez Bejarano, las dudas de muchos "doctos críticos" acerca de la autenticidad de esa atribución se deben en parte a que Vargas tiene como modelo "una insoportable novela epistolar, publicada en España antes de la emigración de Blanco a Inglaterra, con el título de Cornelia Bororquia (Méndez Bejarano, 1920, pág. 442). Bejarano no parece haber leído la novelita de Luis Gutiérrez, que hoy conocemos gracias a la citada edición de Gérard Dufour. Se trata, es verdad, de una obra de importancia secundaria, pero bien pensada, bien escrita y sobre todo, como observa Dufour, sólidamente asentada sobre un fondo ideológico que deriva de los filósofos ilustrados, en especial de Voltaire (Gutiérrez, 1987, pp. 42-44). Blanco White pudo conocer la novela en Sevilla, en Madrid o en Inglaterra, en cualquiera de las 13 ediciones que aparecen entre 1801 y 1822, algunas de ellas impresas en Londres.

La historia central de Vargas y los personajes principales provienen indudablemente de Cornelia Bororquia. Pero la acción se multiplica en gran cantidad de episodios de variado tipo: escenas costumbristas, duelos de capa y espada, viajes, subterfugios y engaños, milagrerías fraguadas o imaginarias, comidas; todo salpicado de sales humorísticas, de diálogos llenos de mordacidad e ingenio en los que se oyen los ecos de dialectos y regionalismos de toda España. Blanco White ha extendido además el argumento uniendo las historias de Cornelia y de Antonio Pérez, tejiendo alrededor de ellas incidentes, cómicos y trágicos, y modificando de modo muy significativo dos momentos fundamentales en el desarrollo del relato: el retiro pastoril en el que Vargas se ponía en contacto con la religión natural, e indirectamente con el pensamiento de Rousseau, se suplanta ahora por el breve viaje a Inglaterra en el que se produce su conversión; y el final trágico de Cornelia Bororquia se convierte en un final feliz, más acorde con la justicia poética y sentimental. Los personajes de Vargas adquieren también dimensiones distintas. Vargas, que en la novela de Gutiérrez era un joven incapaz de una acción heroica, crece en Blanco White y se convierte así en auténtico protagonista tanto en los episodios que rodean el aprisionamiento de Antonio Pérez como en el rescate de Cornelia y la consiguiente huida de la pareja a Inglaterra. El autor vuelca sobre el héroe, en muchos aspectos, las características de su propia psicología y las experiencias de su vida personal, convirtiéndolo en un personaje autobiográfico. Meneses se transforma en un auténtico caballero y sus escaramuzas y engaños para rescatar a Cornelia de las manos del astuto arzobispo constituyen los mejores momentos de la novela. Cornelia, en cambio, pierde algo de la tesitura trágica, propia de una Juana de Arco española, de la novelita de 1801; en la entrevista con el arzobispo hierve de indignación y adquiere estatura casi heroica; pero a partir de ese momento se empequeñece y se torna la sumisa compañera de Vargas. El arzobispo, pintado con tintas extremadas, es una araña negra, un insecto lleno de pasiones y de bilis, incapaz de manifestar un sentimiento humano, ni siquiera una sincera emoción amorosa; no ocurre así, en cambio, con el 
arzobispo de Cornelia Bororquia, que experimenta una real pasión y antes de morir recupera cierta dimensión humana.

La novela de Blanco White se destaca sobre todo por la variedad y riqueza de los personajes secundarios: el padre Cacafuto, Maese Roca, los muleteros, los nobles y criados del castillo de Alange, la marquesa de Montemolín, los gitanos que ayudan a Vargas, adquieren por momentos rasgos de individualidad que superan la determinación costumbrista. Hasta los animales manifiestan en Vargas personalidad; cada una de las mulas tiene comportamiento distinto, y la cabalgadura de Meneses, muy acorde con el idealismo de su dueño, se destaca por su elegante porte y su belleza.

Vargas es, a diferencia de Cornelia Bororquia, una novela histórica. La vinculación de las historias de Antonio Pérez y de Cornelia resulta verosímil ya que ambos personajes fueron víctimas de procesos inquisitoriales durante el reinado de Felipe II: en 1559 Cornelia, y en 1574 Antonio Pérez. Ambos procesos aparecen detalladamente descritos en la Historia crítica de la Inquisición en España de Juan Antonio Llorente. En el tomo III se dedican varios capítulos a las intrigas políticas que determinaron la acusación del ministro, su huida a Francia y a Inglaterra y el auto de fe condenatorio in absentia (Llorente, 1817-1818, III, pp. 316-345). En el tomo II refiere Llorente las circunstancias que rodean el juicio de las dos Bohorques, María y su hermana Juana (esta última, torturada durante su embarazo, perdió al hijo, como la Cornelia de la novela de Blanco; pero es María la persona real sobre cuya vida y condena se basa la ficción). Como advierte Llorente: "Murieron en el mismo Auto de $\mathrm{Fe}$ (Sevilla, 1559) Doña María de Virués, Doña María Cornel y Doña María de Bohorques, que eran todavía jóvenes, y cuyos padres pertenecían a la más distinguida nobleza. La historia de la última de esas jóvenes merece ser conocida a causa de algunas circunstancias de su proceso, y porque un español ha compuesto con ella una obra bajo el título de Cornelia Bororquia, que es según él una historia más que una novela; pero no es ni una cosa ni la otra, sino un conjunto de cosas y de escenas mal concebidas en las que el autor no ha sabido ni conservar los verdaderos nombres de los actores, ni siquiera de la heroína, por no haber entendido la historia de la Inquisición de Limborch" (LIorente, 1817-1818, III, pág. 266) ${ }^{11}$.

Blanco White cita la obra de Llorente como básica referencia para la Historia de la Inquisición que prepara hacia 1840: en Julio de ese año anota en su diario lo siguiente: "Es mi intención usar la energía mental de que pueda aún disponer para compilar una breve Historia de la Inquisición utilizando los materiales históricos contenidos en la extensa obra de mi infortunado amigo Llorente" (Blanco White, 1845, pág. 197) ${ }^{12}$.

11. Utilizo la edición francesa (Llorente, 1817-1818) por ser la primera y constituir una ficl copia del manuscrito original. Es la edición que Blanco White manejaba. Adolfo de Castro corrige a Llorente en un pequeño detalle: el error de unir los nombres de Cornel y Bohorques deriva de una mal entendida frase de Limborch. (Ca tro, 1851, pp. 433-434).

12. Como se sabe, Blanco procuró una ayuda monetaria de la corona inglesa para Llorente y Moratín. Ver Llorens, 1967, pp. 57-73. 
Los sucesos de Zaragoza, el excarcelamiento de Antonio Pérez, sacado ilegalmente de la manifestación y encerrado en la Aljafería, sede del Santo Oficio, siguen en la novela la cronología y desarrollo de los acontecimientos narrados por Antonio Pérez mismo en la Relación sumaria de las prisiones y persecuciones de Antonio Pérez que Blanco White manejó en la edición de Génova, citada en nota del capítulo XXXI con la fecha equivocada, 1654 por 1644; en la carta de Beamonte, el amigo gaditano de Cornelius, se habla de ella como edición "abominablemente impresa y llena de errores" (Blanco White, 1822b, pp. 10-11). Otra documentación utilizada por Blanco, especialmente en el penúltimo capítulo de la novela, deriva de la Información de Don Lupercio Leonardo de Argensola (Leonardo de Argensola, 1808). El autor respeta fielmente esas fuentes pero las aprovecha en todo aquello que favorece a su intención novelística. Amplía la información sobre ciertas leyes, usos y costumbres, presuntamente fuera del conocimiento de su público. Explica así el sentido de los fueros, el derecho a la manifestación, la lucha entre poderes políticos y religiosos en tiempos de Felipe II, la creencia en los zahoríes, etc. Da vida a personajes históricos como el marqués de Almenara, los La Nuza, el obispo de Teruel, manteniendo un discreto balance entre verdad histórica y ficción; crea en cambio, libremente, los personajes secundarios como doña Engracia o los líderes de los amotinados, siguiendo en la creación de todos ellos los procedimientos típicos de la novela histórica inglesa. El diálogo deriva de la literatura clásica española y presenta un tono arcaico que nos remonta al siglo XVI, sobre todo cuando se trata de nobles; el diálogo popular, que forma parte de la caracterización de tipos costumbristas como la dueña de la pensión, los vecinos y criados, refleja en cambio una más directa observación de la realidad, es mucho más rico, más libre, y se maneja con más moderno sentido del humor y de la gracia.

Como es Vargas un temprana novela histórica escrita en inglés, la comparación con Walter Scott resulta inevitable; pero como afirma Lockhart en el comentario ya citado, no es Walter Scott el único modelo posible. En Sur la manière d'inventer une fable, Mme. de Scudery se había anticipado al novelista escocés estableciendo como regla de oro de ese tipo de novela la fusión de acontencimiento y personajes históricos con otros creados libremente. Vargas, dice el mismo comentarista, tiene que ver con las novelas de Walter Scott, pero supera las de muchos imitadores (Lockhart, 1822, pág. 730). En verdad, muchos de los detalles de color local que Vargas presenta derivan de las crónicas que le sirven de base y no de lecturas contemporáneas. Y la seriedad en el manejo y la transcripción de la información histórica se destaca en Vargas con mayor claridad que en sus posibles modelos.

Es más importante para nosotros determinar la deuda de la novela con la tradición del género en España. En ese sentido, Vargas es la creación característica de un escritor español muy consciente de los valores universales de la novela cervantina y de la novela picaresca ${ }^{13}$. En primer, la estructura en que se

13. Son bien conocidas las muchas menciones de Blanco White a Cervantes y a su obra. En el Bosquexo de la historia del entendimiento en España, publicado en Variedades, I, Enero de 1824, 
enmarca el relato deriva de Cervantes. Un editor ficticio da justificaciones para la publicación de un manuscrito y nos informa sobre el presunto autor, Cornelius Villiers. Cornelius Villiers justifica a su vez la escritura de su obra como resultado de una incitación amistosa y da como prueba la carta de un amigo gaditano. Cornelius Villiers se inserta en el relato interrumpiendo la historia o agregando, al pie de página, notas aclaratorias que sólo sirven para confundir los límites entre la realidad y la ficción. El Quijote es también el intertex to en la composición de personajes y en la creación de incidentes. Hay algunos personajes, como D. Félix Dávila y D. Juan Mendoza, que llevados por sus lecturas de novelas caballerescas y de obras teatrales se comportan como caballeros de farsa, con actitudes ridículas y alambicado lenguaje. El Cervantes que a través de ellos aparece es el Cervantes paródico, el crítico de la sociedad de su tiempo, muy de acuerdo con la interpretación dieciochesca de sus valores. Pero en Meneses se transparenta una dimensión más honda en la lectura de Blanco White. Meneses sufre también delirios caballerescos cuando se trata de sacar a una dama del peligro o defender su honor supuestamente uirajado. Pero el personaje crece en la novela hasta convertirse en el verdadero instigador de las acciones, en el instrumento providencial que juzga y condena los inhumanos excesos del arzobispo y en el héroe capaz de modificar la realidad y modearla de acuerdo con sus propios valores morales. Y a medida que el personaje crece y su idealismo se impone sobre la realidad hasta el triunfo final, crece su dimensión humana, su simpatía y su gracia. Ahora es el Quijote, a través de él, un taumaturgo cuyo alocado ideal transforma el mundo de los hombres en beneficio de un sentido más alto del amor y de la justicia. Como en Cervantes, la alta idealidad de esos personajes contrasta con el materialismo de los pícaros. Blanco White tiene conciencia incluso del sentido etimológico, de uno de los sentidos etimológicos, del término pícaro, que aplica a los hambrientos ayudantes de cocina cuando en el castillo de Alange se arrojan sobre las suculentas sobras de la comida. El ventero, Maese Roca, representa otro aspecto de la picardía, que tiene más que ver con la tacañería económica y el latrocinio. Los episodios de la venta, la adquisición de los sacos de vino, el cambio y la sustracción de las caballerías y, sobre todo, el engaño con que se procura sacar dinero a la duquesa, pobre víctima de la Inquisición, podrían figurar sin desmedro en el Guzmán de Alfarache o en algunas de las novelas ejemplares de Cervantes. El padre Cacafuto une en su figura, sus apetitos gastronómicos, su milagrería y su lengua, todos los recursos de comicidad prevalentes en la tradición cervantina, sea en la vertiente española o en

manifiesta indirectamente la idea, casi pre-unamuniana, de que el Quijote entendido como simple parodia de la caballería ha causado un mal al espíritu español, pues lo apartó del quijotismo de los siglos anteriores. Por consiguiente, existe otra posible lectura que habrá de devolver esa perdida dimensión. En su propia novela objetivará, pues, en personajes como Don Felix y Meneses, esas dos interpretaciones contradictorias. Hay también sobradas referencias en las Letters... y en otros escritos a la novela picaresca. En Febrero de 1837, Blanco está releyendo el Gil Blas de Lesage, en una bonita edición con viñetas. Considera que los españoles no deben lamentar demasiado el plagio de Lesage, cuya mente compara con una serpiente ágil, flexible, fría y lista para clavar los dientes. La humanidad del Gil Blas, y tal vez de toda la picaresca, le parece "una tribu de reptiles". (Blanco White, 1822, pp. 279-280). 
las múltiples estribaciones de esa tradición en las literaturas europeas. No es extraño que Blanco cite, tanto en las Cartas como en Vargas, a Hudibrás, John Gilpin y a otros personajes de sátiras inglesas diseñados sobre el modelo del Quijote. Cacafuto es un Sancho Panza glotón, astuto y milagrero. Hay algo en él, sin embargo, de bufonería italiana. En su retrato, en que se conjugan la dureza de la crítica articlerical y la bonhomía, se dan la mano Cervantes y Boccaccio, como ocurre frecuentemente en la novela y en el teatro europeos cuando reflejan la influencia del Quijote.

Hay algunos elementos en Vargas que muestran con claridad la conexión íntima entre ciertos recursos efectistas de la novela dieciochesca y la denominada novela popular del siglo XIX. El humorismo grotesco tiende ya a complacer a un público vasto y poco instruido, y el evidente deseo del autor de lograr el beneplácito de sus posibles lectores lo lleva a extenderse demasiado, en perjuicio de la economía del relato, en la descripción minuciosa de las picardías del ventero o de los exabruptos y milagrerías del padre Cacafuto. Lo mismo ocurre con los rasgos de sentimentalidad, que adquieren por momentos dimensiones patéticas. Son también típicos de la novela popular española ciertos rasgos que molestaban a Lockhart. Vargas es una novela de aventuras; los acontecimientos se suceden en una incesante y vertiginosa cadena, en detrimento de la caracterización profunda de los personajes y del desarrollo de un tema. El autor se esfuerza por dar coherencia lógica a los múltiples incidentes de la obra, pero muchos de los sucesos ocurren azarosamente. Los encuentros más importantes, como el de Meneses y Vargas, el de Vargas, Fray Lorenzo y la marquesa de Montemolín, el de don Félix y su ignorado hermano, y el de Perico y Vargas en Zaragoza, son absolutamente casuales; en los dos momentos en que Vargas está dispuesto a huir de Sevilla, circunstancias fortuitas lo ayudan en su propósito: topa con Mendoza, que está a punto de zarpar para Inglaterra, y sorprende a unos arrieros discutiendo oportunamente el viaje a Madrid al que se unirá de inmediato. En una palabra, el azar juega ya en Vargas el importante papel que tiene en las novelas folletinescas; y como ocurre en esas novelas, el narrador maneja el relato a su antojo, pasando de lugar a lugar, remontando el pasado o anticipándose al futuro; posee una llave que abre las puertas más secretas, en este caso las de la Inquisición; sus constantes y a veces enojosas interrupciones nos anuncian el propósito de transportarnos a otro ambiente y a otras escenas, sin dejarnos saber a veces, como en el episodio de la noble dama perseguida por la Inquisición, cuáles son las causas y las consecuencias de un determinado incidente. La omnisciencia se restringe cuando se trata de la información más necesaria, como ocurre con la espeluznante historia del infanticidio, y en general con los sucesos que rodean el nacimiento de Vargas. Algunos sucesos o las acciones de ciertos personajes no tienen demasiada justificación, como ocurre con los caprichosos silencios del marqués o con su absurda fidelidad hacia el miserable arzobispo, actitudes que le impiden proteger debidamente el honor y la libertad de su hija. Como ocurre en los folletines, los innecesarios secretos o las palabras mal entendidas provocan la larga separación de los amantes y son la razón de muchos de sus infortunios. 
El autor evidencia, sin embargo, gran brillantez y talento en los pasajes decididamente románticos en que los principios doctrinarios dan lugar a una visión más profunda de la vida humana. Es evidente, sobre todo en la comparación con Cornelia Bororquia, que blanco White tiende a abandonar el tipo de novela filosófica en la que los personajes solían ser ejemplos de una doctrina desarrollada como un ensayo a lo largo del relato. En la novelita de Luis Gutiérrez ese carácter es aún preponderante; en Vargas ocurre sólo por momentos, cuando se ataca decididamente a la Inquisición o aspectos de la clerecía. De cualquier manera, el fondo filosófico existe, pero no abotarga o paraliza la vitalidad de los personajes que, aunque representan ideas, tienen un carácter individual, una dimensión humana, que los aparta del símbolo. El padre Lorenzo, por ejemplo, el ermitaño culpable del supuesto infanticidio, parece, por el furor de su manía religiosa y la violencia de sus alucinaciones diabólicas, una figura desprendida de Shakespeare. Por un lado, es el anacoreta que al extremar sus penitencias adquiere un carácter satánico; pero un resorte trágico mueve sus acciones. Como un Rey Lear deambula por el yermo inquiriendo la razón de su destino; o como Macbeth, experimenta en el fuego de su pasión y de su culpa un castigo infernal anterior a la condena. Vargas tiene también rasgos románticos: es un ser por naturaleza triste, o como dice el autor con un término apropiado a la época que se describe, melancólica; indiga demasiado la razón última de sus acciones, de sus modos de pensar y de sentir. Sus estados de felicidad y de alegría, reducidos a los capítulos finales, nos convencen menos que sus tristezas, y apenas compensan los lamentables padecimientos que se desencadenan sobre él fatídicamente desde el comienzo de la novela. Los tópicos característicos de la novela dieciochesca, como el incesto (Vargas se casa con quien podría ser su hermana), el infanticidio, la violación y en general el crimen, se analizan ahora desde una perspectiva pesimista y por momentos desesperanzada. El asesinato, motivo tan presente en los folletines decimonónicos, es el punto central de ese pensamiento, pues en él se evidencia la naturaleza humana en su nivel más animal, y quizá más esencial. Blanco White presenta dos ejemplos extremados y los conjuga: el joven soldado que canta junto a la ermita de Fray Lorenzo ha cometido un asesinato y no siente por ello culpa alguna; Fray Lorenzo, que es sólo autor de un crimen imaginario, siente la culpa y el más duro remordimiento. En ambos personajes se trasluce la presencia de Satán; y de un Satán más agresivo y más terrible que el sátiro o diablillo de la lujuria y de la perversión sexual, presente en la composición del arzobispo. La confrontación del bien y del mal se expresa directamente en la lucha entre personajes, como Meneses y el arzobispo, en las contradicciones de la historia y en las controversias teológicas; y de modo más indirecto se manifiesta también, simbólicamente, en los paisajes sublimes o pintorescos. Pero es, sobre todo, el recinto del alma la arena en que ambas fuerzas se encarnizan y se aniquilan. Como en el Caín de Byron, el bien y el mal forman en Vargas el tejido de la realidad; y las honduras, los precipicios, los valles de flores y los luminosos cielos andaluces constituyen el 
vehículo objetivo que nos transporta a una geografía interior en que Dios, o la ausencia de Dios, plasma o esculpe a hierro y fuego los misteriosos hontanares del espíritu humano.

\section{REFERENCIAS BIBLIOGRÁFICAS}

ANÓNIMO, 1822. "Vargas; or A Tale of Spain", en "New Publications with Critical Remarks", The New Monthly Magazine and Literary Journal, London Henry Colburn and Co, vol. VI, pág. 461.

BLANCO WHITE, José María. 1822a. Letters from Spain by Don Leucadio Doblado, London, Printed by Henry Colburn and Co.

-1822b. Vargas: A Tale of Spain, London, Baldwin, Cradock and Joy.

-1825a. Practical and Internal Evidenc against Catholicism, in six letters addressed to the impartial among the Roman Catholics of Great Britain and England, London, John Murray.

-1825b. The Poor Man's Preservative against Popery, London, Rivington.

-1833. "Atmos the giant", en Lady Mary Fox (ed), Friendly Contributions for the Benefit of three Infant Schools in the Parish of Kensington, London, R. Milliken.

-1845. The Life of the Rev. Joseph Blanco White. Written by Himself; with Portions of his Correspondence. Edited by John Hamilton THom., London, John Chapman.

-1972. Cartas de España, traducción y ed. Antonio GaRNICA, introducción de Vicente Llorens, Madrid Alianza.

-[1972] 1974. Obra inglesa de José María Blanco White, ed. Juan Goytisolo, Barcelona, Seix Barral.

-1975. Autobiografía, ed. Antonio GaRnICA, Sevilla, Universidad de Sevilla.

- 1975. Luisa de Bustamante o la huérfana española en Inglaterra y otras narraciones, ed. Ignacio Prar, Barcelona, Labor.

—1982. España, introducción, traducción y ed. María Teresa de Ory ARrIAGA, Sevilla, Alfar.

-1993. Conversaciones americanas y otros escritos sobre España y sus Indias, ed. Manuel Moreno Alonso, Madrid, Cultura Hispánica.

BOHEMER, Edward. 1874. Biblioteca Wiffeniana. Spanish Reformers of two Centuries from 1520. Their Lives and Writings according to the late Benjamin B. Wiffen's Plan and with the use of his Materials, Strasburg, K. Trübner.

BROWN, Reginald. 1953. La novela española. 1700-1850, Madrid, Dirección General de Archivos y Bibliotecas.

CASTRO, Adolfo de. 1851. “Ha existido Comelia Bororquia?”, en Historia de los protestantes españoles y de su persecución por Felipe II, Cádiz, Imprenta de la Revista Médica, Apéndice II, pp. 433-434.

CURRY, Kenneth. 1965. New Letters of Robert Southey, edited by Kenneth CURRY, New York and London, Columbia University Press.

ELLIOT, A.R.D. 1964. "Reviews and Magazines in the Early Years of the Nineteenth Century", en Cambridge history of English literature, Cambridge, University Press, vol. XII, "The Nineteenth Century", Part One, pp. 140-163. 
FERNÁNDEZ MONTESINOS, José [1955] 1973, Introducción a una historia de la novela en España en el siglo XIX. Seguida del esbozo de una bibliografía española de traducciones de novelas (1800-1850), Valencia, Castalia.

FERRERAS, Juan Ignacio. 1973. Los orígenes de la novela décimonónica, 1800-1830, Madrid, Taurus.

-1979. Catálogo de novelas y novelistas españoles, Madrid, Cátedra.

FOX, Henry Edward. 1923. The Journal of the Hon. Henry Edward Fox (Afterwards fourth and last Lord Holland), London, Thornton Butterworth Limited.

GUTIÉRREZ, Luis. [1801] 1967. Cornelia Bororquia o La victima de la Inquisición, edición de Gérard Dufour, Alicante, Instituto Juan Gil Albert.

HALKETT, Samuel y John LAING, 1882-1888. Dictionary of the Anonimous and Pseudonymous Literature of Great Britain; including the Works of Foreigners Written in, or Translated into the English Language, Edinburgh, W. Paterson.

LANG, Andrew. 1897. The Life and Letters of John Gibson Lockhart, London, John C. Nimmo.

LEONARDO DE ARGENSOLA, Lupercio. 1808 Información de los sucesos del reino de Aragón en los años de 1590 y 1591, en que advierte los yerros de algunos autores. Madrid, Imprenta Real.

LOCKHART, John Gibson. 1822. "Vargas or A Tale of Spain", Blackwood's Edinburgh Magazine, XII, Diciembre pp. 730-740.

LLORENS, Vicente. 1954. Liberales y Románticos. Una emigración española en Inglaterra (1823-1834), México, El Colegio de México.

-1967. "Moratín, Llorente y Blanco White. Un proyecto de revista literaria", Literatura, Historia, política..., Madrid, Revista de Occidente, pp. 57-73.

-1971. José María Blanco White: Antología de obras en español, Barcelona, Labor.

-1972. "Blanco White and Robert Southey: Fragments of a correspondence" Studies on Romanticism, 11, 2, pp. 147-152.

LLORENTE, Juan Antonio. 1817-1818. Histoire critique de l'Inquisition d'Espagne despuis l'époque de son établissement, jusqu'au règne de Ferdinand VII, tirée des pièces originales des archives du Conseil de la Supréme et de celles des Tribunaux subalternes du Saint-Office par D. Jean Antoine Llorente... Traduite de l' espagnol sur le manuscrit et sous les yeux de d'Auteur, par Alexis PELLIER, Paris, Imprimerie de Plassan.

MÉNDEZ BEJARANO, Mario. 1920. Vida y obra de D. José Ma Blanco y Crespo (BlancoWhite). Madrid, Tipografía de la Revista de Archivos, Bibliotecas y Museos.

MENÉNDEZ PELAYO, Marcelino. 1932. Historia de los Heterodoxos Españoles, Madrid, Victoriano Suárez, vol. VII, pp. 173-214.

MURPHY, Martin. 1989. Blanco White: self banished Spaniard, New Haven and London, Yale University Press.

PATTISON, Samuel Rowles. 1880. The brothers Wiffen: memoirs and miscellánies, London, Hodder and Stoughton.

ROMERO TOBAR, Leonardo. 1976. La novela popular española del siglo XIX, Barcelona, Ariel.

STEPHEN, Keskie y Sidney LEE. 1968. The Dictionary of National Biography, Oxford University Press. 